CÓMO CITAR ESTE ARTÍCULO:

Betancur, A. y Pérez, M. (2017). La tierra, cambios en su uso y la relación con la transformación sociocultural: impactos directos a las comunidades campesinas a través de la implementación de actividades mineras. Revista de Sociología y Antropología: VIRAJES, 19 (1), 189-208. DOI: 10.17151/ rasv.2017.19.1.10

\title{
LA TIERRA, CAMBIOS EN SU USO Y LA RELACIÓN CON LA TRANSFORMACIÓN SOCIOCULTURAL: IMPACTOS DIRECTOS A LAS COMUNIDADES CAMPESINAS A TRAVÉS DE LA IMPLEMENTACIÓN DE ACTIVIDADES MINERAS*
}

\author{
ANGIE BETANCUR VARGAS** \\ MARGARITA MARÍA PÉREZ OSORNO***
}

Recibido: 19 de diciembre de 2016 Aprobado: 11 de febrero de 2017

Artículo de Reflexión

\footnotetext{
* Este artículo corresponde a un artículo de reflexión.

** Administradora en salud: énfasis en gestión sanitaria y ambiental, Colombia. Correo electrónico: anibetancur@hotmail.com. Egresada Facultad Nacional de Salud Pública - Universidad de Antioquia. (1) ORCID: 0000-0002-7662-5408

*** Administradora en salud: énfasis en gestión sanitaria y ambiental/especialista en Salud Ocupacional/ Magíster en Epidemiología (Universidad de Antioquia). Candidata a doctor en Desarrollo Sostenible (Universidad de Manizales), Colombia. Correo electrónico: margarita.perez@udea.edu.co. Afiliación institucional: docente Facultad Nacional de Salud Pública - Universidad de Antioquia.

(1) ORCID: 0000-0002-7178-9702
} 


\title{
Resumen
}

Colombia ha reemplazado su modelo económico basado en la agricultura, por la implementación del desarrollo de la minería, situación, que ha generado una serie de transformaciones en cuanto a la relación del país con la tierra. Objetivo. Identificar como la tierra y el cambio en el uso de esta se relaciona con la transformación en la vida cotidiana del campesinado colombiano a raíz de la implementación de la actividad minera en sus territorios. Metodología. se realizó una revisión documental con énfasis reflexivo. Resultados. Se evidencia un detrimento en la dinámica social del campesinado colombiano a raíz de la incursión de la extracción minera en sus territorios. Conclusión. Ambos sectores requieren como base laboral la tierra, el uso de esta y demás recursos naturales, contexto que ha puesto en jaque el tejido social de este tipo de colectividades y ha impactado fuertemente sus estilos de vida, economía y estabilidad económica.

Palabras clave: Colombia, uso de tierras, minería, comunidades campesinas.

\section{THE LAND CHANGES IN ITS USE AND THE RELATIONSHIP WITH THE SOCIOCULTURAL TRANSFORMATION: DIRECT IMPACT ON RURAL COMMUNITIES THROUGH THE IMPLEMENTATION OF MINING ACTIVITIES}

\begin{abstract}
Colombia has replaced its economic model based on agriculture for the implementation of mining development, a situation that has generated a series of changes in terms of the relationship of the country with the land. Objective: To identify how the land and the change in its use relates to the transformation in the daily life of the Colombian peasantry due to the implementation of the mining activity in their territories. Methodology: A literature review was performed with reflective emphasis. Results: A detriment in the social dynamics of the Colombian peasantry following the incursion of mining in their territories is evident. Conclusion: Both sectors require the land as the labor base, its use and the use of other natural resources in a context that has jeopardized the social fabric of such communities and has strongly impacted their lifestyles, their economic and their economic stability.
\end{abstract}

Key words: Colombia, land use, mining, farming communities. 


\section{Introducción}

L a disputa por las tierras, a través de los tiempos, ha caracterizado uno de los pilares de crecimiento y progreso de las civilizaciones, lo cual, ha permitido la creación de territorios, entendiéndose estos como la conjugación de relaciones sociales asociadas con áreas geográficas, estilos de vida, modos de producción, política, economía y cultura, factores que son considerados procesos colectivos del desarrollo poblacional y que directamente dependen de los recursos naturales, siendo estos últimos, los que permiten su conformación como pieza clave para el establecimiento y puesta en marcha de una colectividad. Es pues, el modo de relación de un territorio con la tierra, lo que genera su transformación e identidad.

En las últimas décadas, el gobierno de Colombia, en su afán de visibilizar la nación internacionalmente, y de suprimir la imagen que se tenía del país como promotor de narcotráfico y violencia, ha movilizado toda su industria para desarrollar la llamada "locomotora de crecimiento", la cual brinda como principal producto de exportación internación los diversos minerales preciosos con que cuenta el territorio nacional, permitiendo así, la expropiación de los recursos naturales por parte de industrias trasnacionales de una manera legal; esta nueva ola de 'desarrollo' económico e industrial, ha dejado consigo fuertes disputas por territorios, conflictos sociales y daño ambiental irreparable en la mayoría de departamentos del país.

Colombia, aún hoy es considerada "El Dorado", y el potencial minero de nuestro país es un atractivo internacional para invertir en nuestras tierras. Los gobiernos nacionales de turno no han desaprovechado esta riqueza y entendiendo que se trata de una de las potencialidades económicas del país han generado planes estratégicos como el proyecto Colombia minería 2019, donde se trazan las rutas a seguir en un plan a mediano y largo plazo que pretende ser parte en los Planes de Ordenamiento Territorial y Desarrollo Nacional hasta la próxima década, y en el cual la minería sería una prioridad de producción de materias primas y además generaría la entrada de tecnologías promoviendo el desarrollo nacional. (Quiroga, 2012, p. 16)

Según Rodríguez (2014), para el año 2012 la nación contó con 248 permisos para explotación en más de 337.000 hectáreas (ha), más 510 peticiones en 1.127.000 ha, lo cual representaría la mitad del territorio nacional para ser producto de minería a gran escala, no contándose con los territorios en donde subsiste la minería ilegal.

Lo anterior evidencia el apoyo que ha brindado el Estado a la 
industria minera, y como "no se puede servir a dos señores a la vez", es un breve panorama del abandono por parte del gobierno con que cuentan comunidades enteras como campesinos, afrodescendientes e indígenas, los cuales, han tenido que 'salir' de sus tierras o sumarse (casi que forzados) a este modo de producción, para así seguir subsistiendo, tratando de coexistir con esta industria.

Este artículo pretende identificar como la tierra y el cambio en el uso de esta se relaciona con la transformación en la vida cotidiana del campesinado colombiano a raíz de la implementación de la actividad minera en sus territorios, representando estos elementos unos de los impactos directos de la puesta en marcha de este sector industrial.

\section{Método}

Con el fin de identificar cómo la tierra y el cambio en el uso de esta se relaciona con la transformación en la vida cotidiana del campesinado colombiano a raíz de la implementación de la actividad minera en sus territorios, representando estos elementos unos de los impactos directos de la puesta en marcha de este sector industrial, se realizó una revisión documental con énfasis reflexivo, en la cual se empleó el método cualitativo; tomando como referencia, la consulta de boletines informativos, libros, artículos de investigación y documentos electrónicos, los cuales fueron respectivamente sistematizados y analizados.

\subsection{Estrategias metodológicas}

Esta investigación se ejecutó por medio del desarrollo de dos etapas: la primera denominada "consulta de la información", en la cual se llevaron a cabo, los procesos de investigación y elección de la documentación, y la segunda llamada "análisis de la información", que permitió hacer la validez y la comparación de la información obtenida.

\subsection{Procedimiento}

Los documentos investigados se consultaron en diversas bases de datos, para posteriormente, agrupar la información suministrada en tres categorías clave de objeto de estudio: afectación a la población campesina, debido a la transformación del uso de sus tierras como base de extracción minera, percepciones de 'campesinos' que han luchado por la defensa del derecho a sus tierras e implicaciones directas de la minería en las comunidades campesinas. 
Finalmente, la información obtenida se sistematizó y analizó, y a continuación se presentan los principales resultados.

\section{Resultados}

La población rural o como comúnmente se denomina en la jerga popular, los campesinos, representan un importante motor del desarrollo del país, puesto que gracias a la labor que estas comunidades ejecutan, los demás habitantes de la nación, tienen la posibilidad de alimentarse y subsistir; representando pues, una de las esferas económicas más importantes para sostenimiento interno de Colombia.

Actualmente la población rural es el 53\% de la población del planeta y la agricultura continúa siendo la actividad económica que mayor empleo genera. En el Tercer Mundo, con la excepción de América Latina, los habitantes del campo superan numéricamente la población de las ciudades. (sic). (Naciones Unidas. Word Urbanizations Prospects como se citó en Florero, 2003, p. 2)

Según Florero (2003), en Colombia, las personas que residen en las zonas campesinas, representan el 31\% del total de la población nacional, y si se suma a este, las comunidades que viven en pequeñas cabeceras municipales, donde el número de habitantes es menor de 10.000, el área rural sería de $38 \%$; a pesar del alto grado de migración de los campos a las ciudades, esta población representó un incremento en el siglo XX.

Pese a que las cifras anteriores, se extrajeron de una investigación realizada en 2003, en la actualidad, este panorama no ha cambiado, al contrario, se evidencia un leve aumento de la población campesina nacional, la revista Semana en una edición especial realizada en 2012, titulada "Así es la Colombia rural", señala que el $94 \%$ del territorio nacional es considerado área agraria, y de este, solo un $32 \%$ de la nación reside allí, porcentaje poblacional que se ha convertido en blanco de constantes disputas por sus territorios, bien sea por grupos armados ilegales o incluso por el mismo gobierno: “Durante más de cuatro décadas el campo ha sido escenario de violencia, pobreza y reformas fallidas o inconclusas(...) Hay múltiples conflictos relacionados con el uso y la tenencia de la tierra, y una deuda social enorme" (Semana, 2012).

Lo anterior da a conocer uno de los muchos impactos de la vida cotidiana del campesinadocolombiano tras la puesta en marcha deun modelo económico basado en la minería: la disputa territorial, la cual se centra no solo en el accionar armado ilegal, sino también en el interés del gobierno 
nacional por expandir su poderío y soberanía por medio de la licitación de títulos mineros y concesiones de permisos de exploración, contexto que a la par, genera una oleada de violencia, hostigamientos y desplazamiento civil de la población. Según la agencia de noticias Universidad Nacional (2011), en el Seminario Internacional Minería, Territorio y Conflicto en América Latina, que se llevó a cabo dentro de las instalaciones de esta institución, poblaciones campesinas que a su vez son afrodescendientes, denunciaron como su territorio (La Toma, en el municipio Suárez, Cauca), se ha convertido en víctima del conflicto, despojo de tierras, vulneración a su modo de producción e identidad cultural debido a la incursión de proyectos mineros propiciados por el Estado en sus tierras.

Esto demuestra otra de las realidades que padecen los campesinos colombianos tras la ejecución de proyectos de explotación minera en sus dominios: pérdida de su capacidad productiva (ya que la tierra perteneciente a estos es licitada a multinacionales, o la poca que les corresponde se ve perjudicada por los estragos ambientales generados por este tipo de labor) y detrimento a su identidad cultural, (tras los mínimos recursos recibidos de su actividad, muchos se ven obligados a buscar otros medios de subsistencia, incluso aquellos que van en contra de las ideas conservacionistas al medio ambiente que propician su ocupación).

Lo anterior se relaciona a otro tipo de implicación social y económica devengada al fenómeno extractivo del país en este tipo de poblaciones: el nivel de desigualdad y la concentración de la tierra:

La concentración de la tierra y la desigualdad han crecido en la última década en el campo. El índice Gini rural, que mide la desigualdad, pasó de 0,74 a 0,88. (...) La mayor concentración de la propiedad está en las zonas ganaderas y en las que se explotan recursos naturales. (Semana, 2012)

Pero, ¿por qué se disputan tanto estas tierras si según el índice de Gini sus pobladores encabezan la lista de nacionales con mayor tasa de desigualdad y pobreza?, como bien se dijo, "sus pobladores" son los 'pobres', mas no la tierra en la que ellos viven, el mismo comunicado de Semana (2012), informa que 5,8 millones de hectáreas han sido concedidas dentro de los 9.000 títulos mineros vigentes y hay 20.000 nuevas peticiones; hectáreas que según el mismo artículo de prensa, representan más de la proporción de lo que hay sembrado nacionalmente en comida.

Lo anterior es preocupante porque deja en evidencia que al Estado le es más beneficioso expropiar a naturales de sus tierras, limitar la posibilidad de siembra para los alimentos de los demás habitantes de la nación y 
contaminar los recursos naturales, que frenar el incremento de expedición de títulos mineros. Contexto que permite mostrar otra de las problemáticas generadas al campesinado por la incursión de proyectos extractivos: la pérdida de tierras, las cuales no sólo son empleadas para comercializar sus productos, sino también para subsistir, convirtiéndose estas en la base de su propio tejido y dinamismo sociocultural.

Todo este escenario que ha sido estudiado hasta el momento, ha generado la movilización de las comunidades campesinas, con el fin de defender sus territorios y sus derechos como colombianos; a continuación, se relatarán ciertos casos en donde se evidencian algunos impactos causados por el desarrollo de la actividad minera en sus tierras y comunidades.

\section{Afectación a la población campesina debido a la transformación del uso de sus tierras como base de extracción minera}

Cuando se habla de minería es estrictamente necesario hablar de territorio, en el momento que un proyecto minero se otorga en determinada área geográfica, este tiene repercusiones para toda la región con la cual va a interactuar, máxime, cuando el sustento y la base productiva de esta depende de los suelos, agua y demás recursos naturales, elementos que obligatoriamente o se deben compartir o se deben propiciar en gran medida a este tipo de proyectos, situación que genera una serie de transformaciones sociales y ambientales, obligando a las comunidades a optar por implementar otras formas de organización; siendo esta otra de la implicaciones sociales derivadas de la incursión de proyectos mineros en las tierras campesinas: estas colectividades, no solo ven amenazadas sus tierras al momento de llegada del sector extractivo, también sienten una gran intimidación en cuanto al detrimento de su cultura, su modo de vida, su relación con el entorno natural, sus medios de producción, sus procesos económicos e incluso sociales.

Así pues, lo anterior indica la importancia de entender el término 'territorio' como un todo, como la suma de un conjunto de diferentes formas de organización de una comunidad, como la interacción de esta con el medio ambiente, con su cultura, con sus medios de producción, con sus propiedades, con sus políticas, con sus relaciones sociales, etc.:

La delimitación de un territorio, más que el trazado sobre un espacio, implica la señalización de fronteras frente a otros. Se trata de poner límites a la acción de otros y en la práctica histórica, de regir el comportamiento, la posibilidad y la forma de la vida de otros, sus semánticas y su comprensión de la existencia (sic). (Lozano, 2009, citado en Quiroga, 2012, p. 83) 
En Colombia, un impacto común que se vivencia en las comunidades afectadas por el desarrollo de la minería, es la violencia y la constante conflagración entre proyectos mineros, gobierno y sociedad civil, debido a la generación de concentración de tierras de parte de las multinacionales, lo que ha implicado la pérdida de la capacidad productiva, detrimento de tejido sociocultural y desfase en la economía propia de estas colectividades, ya que su único medio de subsistencia es arrebatado de sus dominios y privatizado por esta industria, situación que a su vez complica las relaciones sociales y culturales debido a que este hace parte de la base de su dinamismo sociocultural. A continuación, se trae a colación un estudio que da a conocer las implicaciones producidas por esta actividad en parte del territorio antioqueño.

Como lo estudia Quiroga (2012), la subregión del Nordeste de Antioquia es una de las zonas con mayor producción de oro del país, aportándole pues el $27 \%$ del total de su obtención nacional, situación que ha sido motivo de fuertes disputas entre los actores sociales que se desenvuelven allí: por un lado, se encuentra el sector de la industria minería, el cual, solo busca explotar a gran escala los recursos de la zona, generando detrimento ambiental debido al uso de químicos, tala masiva de bosques y explotación sin límites de los recursos naturales propios del lugar. Por otro lado, están los mineros artesanales y campesinos, quienes combinan varias actividades económicas de subsistencia como la minería artesanal, ganadería y agricultura. A este factor se le suma el conflicto social y armado que ha azotado la zona desde hace años.

Al ser este espacio geográfico (municipios de Remedios y Segovia específicamente) deinterés mineronacional einternacional y encontrarse en el centro de los planes nacionales de desarrollo como una zona de interés industrial. Las comunidades campesinas, el Estado y la presencia multinacional, entran en conflicto permanente generando formas territoriales de organización de acuerdo a los intereses particulares. Para la comunidad campesina este conflicto socio-territorial pasa por una reivindicación del derecho al territorio de forma integral, pues es allí donde se reproduce la vida y la cultura, promoviendo la construcción alternativa de escenarios de resistencia. De otro lado, encontramos un contexto de acumulación y concentración de la propiedad en manos de las grandes empresas mineras; de exclusión y olvido de las comunidades por parte del Estado, el cual a partir de la concesión de títulos mineros ha privilegiado a estas grandes multinacionales en contraposición con los pequeños mineros y mineros artesanales y solamente a través de políticas asistencialistas ha beneficiado a la población minero campesina de la región (sic). (Quiroga, 2012, p. 15) 
La expedición frenética de títulos se ha vuelto un panorama habitual a lo largo del territorio nacional, dando más importancia a las iniciativas de las empresas de este sector, por encima del bien común de la nación; si no se poseen estructuras gubernamentales que privilegien el medio ambiente y la sociedad civil, sobre las diversas actividades económicas que se llevan a cabo dentro de la dinámica financiera del país, ¿qué ocurrirá cuando ya no se puedan explotar más recursos?, ¿cómo se estructurará la nación sin medios naturales, tierras aptas para la agricultura, y ríos completamente contaminados?, ¿es rentable la extracción minera para el futuro de la biodiversidad del país?

En Colombia, la solicitud de títulos mineros, prácticamente se ha convertido en una futura licencia de explotación, claro está, si se es poseedor de una empresa rentable y reconocida en el sector, ya que estas no se otorgan a cualquier persona, tienen que demostrar su posibilidad de explotar masivamente los recursos, situación que ha puesto en jaque al sector agrícola del país, puesto que las tierras empleadas para este propósito, han sido reemplazadas por vastas zonas de explotación minera, lo que deriva, no solo en un problema civil para el entorno rural, porque no sólo se les están negando sus únicos medios de subsistencia económica sino también sus bases sociales y culturales, privando a la vez a la nación, de gozar de una adecuada seguridad alimentaria.

En 2012, El Espectador publicó en una de sus noticias, la preocupación que presentaba el Ministro de Agricultura de la época, Juan Camilo Restrepo Salazar, tras la constante aprobación de títulos mineros en el país, lo cual, impedía la titulación, a los campesinos, de 24,71 millones de hectáreas de tierras baldías, el equivalente al 79,6 por ciento del territorio rural colombiano, el ministro señaló que según la Ley 160 de 1994, en su artículo 67, "no serán adjudicables los terrenos baldíos situados dentro de un radio de cinco kilómetros alrededor de las zonas donde se adelantan explotaciones de recursos naturales no renovables". Restrepo, en ese mismo comunicado, alertó sobre los potenciales conflictos que se presentarán en el sector rural colombiano, ya que cerca del $53,5 \%$ de la agricultura y ganadería de la nación, se verá afectada tras el desarrollo de actividades mineras, indicando:

(...) habría 5 millones 363 mil campesinos en riesgo de conflicto con la minería. De seguir así, la crisis social en el sector rural va a ser inmanejable (...) Colombia debe saber explotar sus recursos mineros. No a costa del medio ambiente y de la agricultura porque de lo contrario se pondría en riesgo la seguridad alimentaria del país. (El Espectador 2012). 
Como se puede apreciar, el desarrollo sostenible de la nación está completamente sobrevalorado, lo mismo ocurre con la población rural, la cual solo debe sentarse a ver como es expropiada de sus tierras, identidad cultural y base social, ya que el mismo Estado es quien permite tal vulneración de sus derechos; en el siguiente caso, se puede apreciar el apoyo del gobierno a la industria minera por encima de los derechos de las comunidades campesinas adyacentes a los páramos naturales, promulgación que se hizo a través del Plan Nacional de Desarrollo del nuevo gobierno, a cargo del presidente Juan Manuel Santos.

Lozano (2015) concluyó, tras el estudio del nuevo Plan Nacional de Desarrollo, que la prohibición de la realización de actividades económicas en los páramos colombianos, solo protege a la industria minera para que siga ejerciendo su labor en estas zonas, denominadas "áreas protegida o de reserva": el gobierno, al hacer la delimitación de dichas áreas, tuvo como resultado dos mapas, el primero (elaborado por el Instituto Alexander von Humboldt), cuenta con la delimitación de los ecosistemas existentes en dichos páramos, y el segundo (hecho por el Ministerio del Medio Ambiente, con colaboración de los Ministerios de Minas y Energía y Agricultura), el cual, se basa por la delimitación de criterios económicos, técnicos, sociales y ambientales, y deja en evidencia las zonas donde se tiene interés de ser explotadas. De la misma manera, en el nuevo Plan Nacional de Desarrollo, se da un respiro a las empresas mineras que llevan explotando durante años los recursos de los páramos, asegurando que pueden seguir ejerciendo dicha labor, hasta 2050 o hasta la fecha en que se consuman las reservas de oro, cuando, por obvias razones, no tendrán ningún atractivo, adquirir una nueva prórroga.

\section{Percepciones de 'campesinos' que han luchado por la defensa del derecho a sus tierras}

Tras varias décadas de 'exterminio' de recursos naturales, expropiación de tierras, detrimento al territorio nacional, usurpación de bienes, etc., en los últimos años se ha podido apreciar una creciente ola de manifestación de diferentes grupos sociales, los cuales, de una u otra manera, han pretendido alzar la voz y no callar frente a la destrucción de sus comunidades y modos de vida. Según Rodríguez (2014), en 2014 se llevó a cabo la marcha de varios grupos de mineros artesanales, campesinos y grupos ambientalistas del país, que tenía como objetivo, luchar para detener las actividades de la industria minera a nivel nacional, dicha manifestación tuvo como nombre "La gran minería envenena, eres tú quien la frena"; dentro de los reclamantes, habían representantes de la población minera artesanal, quienes denunciaban estar inconformes con la manera de explotación de este sector industrial, puesto 
que este no tiene en cuenta métodos de extracción segura que permita la regeneración ecosistémica y mitigación de impactos ambientales en el territorio donde ejecutan dicha labor:

Como minero tradicional, Fabio señala que en un momento determinado el impacto en un área de extracción de oro se detiene con la intención de permitir que el ecosistema pueda regenerarse, mientras que, según él, "las empresas no se preocupan por minimizar daños ambientales. (Rodríguez, 2014, p. 2).

Otros de los asistentes a dicho encuentro ponen en evidencia sus preocupaciones, por las transformaciones sociales que han vivido en sus territorios tras la llegada de la minería a gran escala, puesto que se ha propagado el conflicto, bien sea entre los propios habitantes, ya que hay quienes desean la entrada de proyectos mineros y quienes no (situación que deteriora las relaciones sociales del territorio), y entre las empresas mineras y campesinas, debido a la alteración social en dicho entorno, puesto que se propaga la violencia, se deteriora la cultura, se modifican los estilos de vida y se descompone la calidad ambiental del lugar: "Según Albeiro Antonio Alvarado, agricultor y líder en fortalecimiento organizativo, el conflicto más alarmante era entre vecinos, por estar a favor o en contra de la Mazamorras, empresa que ofreció inicialmente vacantes en las minas con salarios engañosos" (Rodríguez, 2014, p. 3).

Asesinatos, agresiones físicas, alteraciones en los ecosistemas, daños en viviendas, aumento de consumo de alcohol y tensión en la población, fueron razones suficientes para rechazar su presencia (...) La disputa pudo saldarse, pero antes hubo trabajadores muertos en circunstancias confusas para Albeiro y los demás campesinos; lo mismo que vastas zonas verdes quemadas por el agua mal oliente que habría brotado de una perforación de 1000 metros de profundidad, cercana a una vivienda que su dueño tuvo que vender a la firma. (Rodríguez, 2014, p. 3).

Lo anterior plasma el contexto que se desarrolla tras la implantación de proyectos mineros en los territorios, puesto que cuando se ponen en juego temas relacionados con lo ambiental y propiedad privada, se comienzan a presentar fuertes disputas entre los perjudicados y quienes buscan un beneficio. Gruenberger, citado por Coronado (2002), afirma: 
Los conflictos socioambientales reflejan una asimetría respecto del acceso a los recursos que confrontan dos tipos de actores: los que pretenden apoderarse o hacer uso de los recursos naturales para lograr beneficios individuales o empresariales, sin importarles la situación de las poblaciones locales y, estas últimas, que defienden sus recursos porque son la base de su subsistencia. (Gruenberger, 1999). Escenarios en los que no se ha presentado ninguna neutralidad del Estado. (Gruenberger, citado por Coronado, 2002, p. 1)

El desarrollo local de un territorio está delimitado, según su forma de aprovechamiento de los recursos naturales propios, cuando llega un tercero a implementar otra manera de aprovechar estos recursos, y si la comunidad no demuestra interés por esta nueva estructura de 'desarrollo', comienzan a surgir una serie de conflictos sociales en relación al medio ambiente, máxime, cuando son actividades casi que impuestas por el gobierno para que se implementen en estas zonas:

Frente al interés mercantilista de dinamizar la economía con un determinado grado de especialización en la explotación hegemónica de los recursos naturales en detrimento de la calidad ambiental y otras formas de aprovechamiento de los recursos, posición sustentada y sostenida por las políticas estatales de las últimas décadas, surge la posición de las comunidades, cuyos intereses han sido subordinados por los modelos de desarrollo, de conservar y promover una distribución equitativa de los beneficios del uso de los recursos naturales. En consecuencia, los conflictos socioambientales surgen de la incompatibilidad de intereses sobre el uso de los recursos y sus impactos. (Coronado, 2002, p. 1)

Según Madrid, Guzmán, Medrano, Mamani y Núñez (2002), los problemas socioambientales de un territorio a causa de la ejecución de la actividad minera, como mecanismo de desarrollo económico predominante, se dan, debido a la amenaza que sienten las comunidades afectadas no solo por el impacto al entorno natural de estas, sino también, por el riesgo de perder las prácticas productivas propias de la población.

El elemento cultural de las comunidades campesinas está profundamente marcado por su interacción con la naturaleza. Esta interacción se da a través de las actividades para la reproducción de su vida, respondiendo a lógicas contrapuestas a las del sistema capitalista. Es una lógica que conceptualiza a la naturaleza como parte integrante de su vida, cada elemento de la naturaleza forma parte de la vida comunal por medio de significaciones. (Madrid, Guzmán, Medrano, Mamani y Núñez, 2002, p. 24). 
Lo anterior deja claro el por qué, de estas comunidades, para defender sus tierras y territorios: si la minería deteriora los recursos naturales de sus entornos, estos se quedan también sin medios de subsistencia.

\section{Implicaciones directas de la minería en las comunidades campesinas}

Robles (2001), en su documento Minería y comunidades campesinas, determina seis efectos directos a las comunidades rurales producto del desarrollo de la minería en sus territorios, los cuales posibilitan visibilizar el panorama que viven estos asentamientos, y los efectos de esta actividad en cada uno de sus aspectos en la vida social, tema que, a su vez, se ha evidenciado en los casos mencionados a lo largo del documento objeto de estudio, y que se sintetizan de la siguiente manera:

- Pérdida de tierras comunales: esta es una de los principales impactos negativos que genera la extracción minera para este tipo de comunidades, puesto que, debido a los títulos mineros otorgados, las colectividades campesinas se ven forzadas a firmar derechos de tenencia de tierras a dichas industrias, lo que convierte a estas empresas como dueñas únicas de la tierra, perdiendo pues, los campesinos el derecho a cualquier tipo de uso de estas.

- Pérdida de aguas de riego: la industria minera requiere gran cantidad de agua para poder realizar la explotación de los minerales, lo cual genera la disminución de los caudales de los afluentes del sector, esto genera que el flujo normal de aguas que los campesinos emplean para irrigar sus cultivos, no sea el apto y suficiente.

- Contaminación de las aguas: este impacto se genera por varios motivos: afluentes residuales del proceso minero que desembocan en las fuentes hídricas, derrame de combustibles a estas y vertimiento de sustancias toxicas como mercurio y cianuro (elementos empleados ampliamente por la industria extractiva).

- Contaminación del espacio: la explotación minera irradia al aire y al espacio general, vapores tóxicos, los cuales generan alteraciones a todo ser vivo próximo al lugar, lo que no solo ocasiona daños en la salud de los residentes aledaños a proyectos mineros, sino también afectación a plantas y animales del territorio.

- Problemas sociales: los proyectos mineros constituyen nuevos asentamientos humanos, los cuales poseen costumbres y estilos de vida diferentes a los lugareños, que pueden generar un choque cultural entre los campesinos y foráneos; unos de estos impactos son: expendio de drogas, abuso de alcohol, conflictos sociales entre los mineros y los lugareños, delincuencia, prostitución, etc. 
- Alteraciones culturales: como se mencionó en el párrafo anterior, las personas que llegan al territorio para trabajar en proyectos mineros, traen consigo diferentes costumbres en cuanto a modo de pensar, vestir, comer, actuar, etc., lo que genera pérdida de las identidades locales, ya que la población, especialmente joven, suele imitar este tipo de comportamientos.

\section{Recomendaciones para mitigar los impactos a las comunidades campesinas}

En la entrevista realizada por El Espectador al doctor Juan Camilo Restrepo en (2012), este dio unas pautas a modo de recomendaciones, con el fin de brindar una solución a las comunidades rurales, víctimas del proceso capitalista, que permite la actividad minera como principal motor de desarrollo del país. A continuación, se citan textualmente dichas sugerencias, ya que se consideran significativas para abordar de una manera más dinámica el tema objeto de estudio:

- Para empezar, necesitamos conocer cuáles son las áreas de reserva minera. La actividad no puede seguir respondiendo a las iniciativas de quienes solicitan los títulos.

- Debe incluir principios que protejan a los colombianos que habitan el campo mediante zonas rurales de exclusión. Las buenas prácticas deben evitar la contaminación del país o la destrucción de sus suelos. No usar veneno, garantizar la reconformación morfológica y no dragar los ríos deben ser algunos puntos de partida. Incluir zonas de exclusión que garanticen la persistencia de la biodiversidad y de los recursos y servicios ambientales. En eso debemos trabajar conjuntamente con el Ministerio de Ambiente y Desarrollo Sostenible (MADS) para lograr una buena selección de los parques naturales faltantes y unir esfuerzos para garantizar el buen manejo del sistema de áreas protegidas. Proteger sólo los páramos y los humedales deja desprotegidos 70,1\% de los tipos de ecosistemas existentes en Colombia (El Espectador, 2012).

\section{Discusión}

Colombia cuenta con un historial de intentos por convertir la explotación minera en una de sus principales actividades de desarrollo económico nacional, en cada etapa histórica que ha vivido el país, la presencia de las actividades agrarias ha marcado fuertemente el contexto económico nacional, hoy en día la actividad rural como uno de los principales métodos 
de expansión financiera de la nación, ha pasado a un segundo plano, dando más predominancia al desarrollo de proyectos mineros.

Piñeiro D, al referirse a la oleada de proyectos similares al minero colombiano en América Latina, diferencia tres etapas que pueden ser de utilidad para rastrear la configuración territorial actual en Colombia. La primera de ellas comprende desde la mitad del siglo XIX hasta 1930, caracterizada por ser una época colonial y un sistema de hacienda, donde la acción colectiva ha sido catalogada con pre política y la concentración territorial dejo cientos de campesinos excluidos de un sistema de garantías. Posteriormente, la etapa de sustitución de importaciones, entre las décadas de los 40 y 50, en donde a partir del agro y la extracción minera, se pretendió regular y controlar la distribución geográfica territorial con varios intentos fallidos. Y finalmente, la etapa que vivimos que comprende desde finales del siglo XX hasta la actualidad, en la cual su enfoque central es la ruptura de institucionalidad nacional y la reacomodación del agro y la industria extractiva al orden mundial. En esta etapa de restauración resurgen y se trasforman las formas de acción colectiva, trasformando a su vez las formas de percibir simbólica y materialmente el territorio construido. (Piñeiro D, citado por Quiroga, 2012, 16)

Lo anterior indica el 'moldeamiento' estructural que el Estado colombiano ha permitido para entrar en competencia con el mercado internacional, obviando la carencia de sostenibilidad de este modo de producción capitalista y olvidando que siendo este, un país en vía de desarrollo, carece de los elementos necesarios para disputar un campo dentro de las mejores industrias mundiales, y máxime si se pretende "luchar" por uno de estos puestos exportando materia prima como lo son los minerales, puesto que si bien, estos otorgan un significante ingreso a la industria que lo extrae, se debe tener presente que de las industrias extractoras presentes en el país, muy pocas pertenecen netamente a Colombia, la mayoría son de origen extranjero, contexto que es inquietante, puesto que se está dejando de lado la producción agrícola, la cual no representa estragos significativos al medio ambiente comparándolo con la extracción minera para darle paso a una industria que lo único que genera son enormes áreas desiertas y sin posibilidad alguna de sobreponerse al impacto de su transformación. El panorama que debe analizar el gobierno es simple: las zonas donde mayor se llevan a cabo procesos de extracción minera en el país, tienen los márgenes de pobreza nacional más significativos. ¿En dónde están tales ingresos provenientes de la industria minera?, ¿en qué bolsillos está 'todo' el dinero que genera este sector? ¡Porque en el de las comunidades 
no está! Solo hay un sinfín de impactos ambientales y deterioro social. Uno de los documentos estudiados, plantea el panorama general de cómo viven los países 'propulsores' de actividad minera como principal medio de desarrollo y subsistencia:

(...) Sin embargo, las comunidades locales y los pueblos tribales de los países ricos en recursos son los más afectados por los efectos perjudiciales ambientales, culturales, sociales y de salud de las actividades de exploración y explotación minera. Urgidos por las políticas macroeconómicas impulsadas por las instituciones comerciales y crediticias internacionales, muchos países empobrecidos se aferran a la minería como actividad "básica" para generar las tan necesarias divisas extranjeras. Hay casos en que como mínimo el $40 \%$ de las exportaciones depende de un solo producto mineral, como el caso del cobre en Zambia, los diamantes en Botswana, la República Centroafricana, Gambia, Liberia y Sierra Leona, el aluminio en Guinea y Surinam, el mineral de hierro en Mauritania. Si bien estos datos son relativamente antiguos (de 1994), ilustran una tendencia que todavía se mantiene. Doce de los veinticinco estados más dependientes de minerales del mundo (la mayoría de ellos concentrados en el África subsahariana) fueron clasificados por el Banco Mundial como "países pobres altamente endeudados", la categoría de países más complicada. (Forest Peoples Programme, 2003, p. 5)

Es ingenuo pensar que Colombia será una de las locomotoras mineras internacionales, analizando los costos-beneficios que genera la minería, se cuentan con más egresos que ingresos:

La gran minería únicamente va a poder ser hecha por multinacionales extranjeras: esas compañías se llevan el 96\% y teóricamente Colombia se queda con el $4 \%$; sin embargo, ni siquiera es el $4 \%$ porque los impuestos que los colombianos pagan son usados para la exenciones tributarias: es decir, los colombianos en su totalidad financian a estas grandes empresas extranjeras para que se lleven el $99 \%$ de nuestros recursos. (Expresa un ecologista colombiano, Director corporativo de la multinacional minera canadiense Medoro en Colombia, citado por Julliet, 2011).

¿Dónde queda la "prosperidad democrática" que hace alarde de poseer el gobierno colombiano, si se prefiere conceder las tierras de la nación a empresas extranjeras para expropiar los recursos nacionales, en vez de propiciar el uso de la tierra para los campesinos, que con su labor, posibilitan el alimento de todo un país? Si más de la mitad de tierra apta 
para cultivo está concedida bajo el titulo minero a otras multinacionales, ¿con qué pretende el gobierno alimentar la nación?, ¿dónde están las garantías y derechos de las comunidades campesinas?

Según expresa la investigadora Guadalupe Rodríguez:

El Ministerio de Minas colombiano considera que la minería es practicable en todo el país, y se han concesionado 43 mil kilómetros cuadrados en 10.000 títulos mineros, 4.000 de los cuales ya están en explotación. El Código Minero vigente, modificado en 2009, no es precisamente respetuoso ni con lo territorial (los proyectos mineros pueden ser declarados de utilidad pública no pudiendo, por ejemplo, un alcalde oponerse a la explotación minera), ni con lo étnico (hay siete resguardos indígenas titulados en su totalidad a la minería), ni con lo ambiental (Colombia es el país más contaminado con mercurio del mundo). Según la Asociación Colombiana de Mineros ASOMINEROS, en 2008 la producción de oro fue de 34.300 kilogramos. (1) (Rodríguez G, ASOMINEROS, citado por Julliet, 2011)

No se respeta la propiedad de tierra, la legislación vigente, los derechos ambientales y los derechos humanos, este es el panorama que deja claro el párrafo anterior, Colombia posee una amplia gama de leyes y normatividad que favorecen a los territorios, pero a la hora de la verdad, vale más el bolsillo de unos pocos que los intereses de muchos.

No sirve mucho que el Gobierno anuncie que será más contundente en erradicar la minería ilegal y que reparará a familias de víctimas en tragedias como la de Santander de Quilichao, si después va a concesionar esas minas a multinacionales como la AngloGold. (Guido, líder social y defensor de derechos humanos del CIMA, citado por Rodríguez, 2014, p. 3)

Es vergonzoso que este tipo de situaciones ocurran en un Estado Social de Derecho, muchas comunidades salen de un 'problema' de explotación ilegal de sus recursos, por medio de denuncias ante el gobierno y después se llevan la enorme sorpresa que por todo lo que lucharon, llegará una industria, que generará mayores impactos debido a que su poder técnico y económico es mayor al de la minería ilegal.

“En Ríosucio y Supía la AngloGold Ashanti ha intentado adelantar actividades de explotación bajo diferentes nombres, reclamando áreas ya concedidas igual que la contratista La Esperanza" (Rodríguez, 2014, p. 1). $\mathrm{El}$ anterior es otro de los casos que viven las comunidades campesinas, 
indígenas y afrodescendientes del país, cuando logran ganar una batalla contra estas fuertes industrias mineras, estas últimas, llegan de nuevo, pero bajo otro nombre. ¿Cuáles son las garantías que ofrece el gobierno a estas comunidades? Porque son claras las garantías que este ofrece a la industria minera.El problema radica en que las comunidades campesinas se deben enfrentar a dos agentes que desean expropiarlos de sus tierras: por un lado se encuentra el gobierno, el cual necesita 'desalojarlos' para así poder proceder con el expendio de títulos a las grandes multinacionales y empresas mineras, y por el otro, las mismas compañías mineras, quienes viéndolos como 'obstáculos', hacen lo imposible para poderlos apartar de su territorio, convirtiéndose en una batalla constante por el acceso y control de los recursos. Pero, ¿quiénes defienden los derechos de las comunidades campesinas si el gobierno está a favor de las multinacionales?

Si bien algunas organizaciones estatales velan por los derechos de los territorios envueltos en problemáticas con industrias mineras, el Estado debe velar por garantizar que se lleven a cabo los procesos de una manera justa sin privilegiar las necesidades de explotación de otros:

Considerando la diversidad de formas comunales y de situaciones que atraviesan las comunidades en los contextos de negociación con empresas mineras en el país, el Estado debiera garantizar que estas cuenten con las herramientas necesarias para poder actuar en esta negociación. Por ejemplo, fomentando la titulación del territorio comunal - no solo la titulación individual- dentro de las comunidades y garantizando que el Acuerdo Previo se dé cuando efectivamente se trate de disponibilidad de tierras y según las formas establecidas (...) Queda en evidencia la necesidad de que las comunidades cuenten con mayor información sobre criterios y valoración de la tierra en contextos mineros. También es importante que el Estado promueva, como política, el fortalecimiento de la institución comunal; por ejemplo, para que cuenten con instrumentos de gobierno y gestión actualizados y saneados. $Y$ en particular, en contextos extractivos, hace falta que el Estado establezca pautas o criterios mínimos de regulación para garantizar que los procesos de negociación entre empresas y comunidades - que se dan en el ámbito privado- se lleven a cabo de manera adecuada: respetando la institucionalidad comunal, los derechos de los comuneros, y en condiciones de mayor acceso a la información. (Burneo y Chaparro, 2010, p. 21)

Una de las entrevistas realizadas en la investigación hecha por Perdomo (2014), señala que si un campesino solicita la obtención de un título para servidumbre de agua, este debe realizar varios procedimientos administrativos para su obtención, proceso que lleva hasta dos años en 
concederse, en cambio, si una empresa minera lo solicita, obtiene este mismo permiso en máximo 15 días tiene los resultados.

La labor agraria ha pasado a ser un segundo plano en la economía nacional, siendo desplazada por la actividad minera, lo cual ha propiciado no solo un impacto social a las comunidades campesinas, sino también en el contexto nacional, puesto que son estos los que permiten la obtención de alimentos; condición, que puede significar una vulnerabilidad de la nación en cuanto a seguridad alimentaria si se ve desde un plano mayor, y debe ser objeto de estudio para así mitigar estragos y evaluar impactos a tiempo para así implementar acciones correctivas.

\section{Conclusiones}

Cuando se habla de territorio y máxime cuando se habla de territorio campesino, necesariamente se debe discutir sobre la tierra y el uso de esta, ya que es a partir de allí donde estas colectividades centran sus bases sociales, culturales y económicas, contexto que se antepone con la dinámica industrial del sector minero, puesto que la finalidad de su labor, genera una privatización de los recursos disponibles en el lugar donde se acentúa, escenario que si se da lugar en comunidades que dependen estrictamente de los suelos, recursos, y uso de estos origina un impacto enorme (como bien se pudo evidenciar a lo largo del documento), el cual se relaciona directamente a la relación de estas colectividades con la tierra y el cambio en el uso de esta, porque es la base de su dinamismo social y cultural, como se pudo apreciar, a tener una pérdida en la disponibilidad de las tierras, se comenzaron a evidenciar disputas territoriales, a elevar los índices de violencia, pobreza (porque se cohíbe su único medio de producción) lo que a su vez se relaciona con el quebrantamiento de la capacidad productiva y medios de subsistencia, el aumento de los niveles de desigualdad, e inestabilidad de los modos de vida, la suma de todos estos factores, generan pérdida de identidad cultural, ya que su base de dinamismo social está limitada y por ende se debilita el tejido social de estas comunidades. 


\section{Referencias bibliográficas}

Agenciade Noticias Universidad Nacional.(2011). Líderes campesinos denuncian desplazamiento por minería. (23 de julio de 2016). Recuperado de http://agenciadenoticias.unal.edu.co/ detalle/article/lideres-campesinos-denuncian-desplazamiento-por-mineria.html

Burneo, M. y Chaparro, A. (2010). Poder, comunidades campesinas e industria minera: el gobierno comunal y el acceso a los recursos en el caso de Michiquillay. ANTHROPOLOGICA, XXVIII (28), 85-100.

Coronado F. (2002). Artículo sobre el libro: Minería y comunidades campesinas de los Andes. ¿Coexistencia o conflicto? Tinkazos, 10(22), 1-4.

El Espectador. (2012). Habría 5 millones de campesinos en riesgo de conflicto con la minería (9 de abril de 2016). Recuperado de http://www.elespectador.com/noticias/economia/ habria-5-millones-de-campesinos-riesgo-de-conflicto-min-articulo-351250

Florero J. (2003). Economía campesina y sistema alimentario en Colombia: aportes para la discusión sobre seguridad alimentaria. Recuperado de http://www.javeriana.edu.co/ear/d_des_rur/ documents/campesinadoysistemaalimentarioencolombia.pdf

Forest Peoples Programme (2003). La Minería y su grave impacto sobre los Bosques y los Pueblos. (Abril, 11, 2016). Eco portal net. Recuperado de http://www.ecoportal.net/ Temas-Especiales/Mineria/La_Mineria_y_su_grave_impacto_sobre_los_Bosques_y_los_ Pueblos

Julliet (2011). El Gobierno beneficia a las multinacionales mineras en detrimento del medio ambiente y las comunidades. Projet Accompagnement Solidaritè Colombie. Recuperado de http://www.pasc.ca/fr/node/3475

Lozano, R. (2015). Páramos para multinacionales sí, para campesinos no. Agencia El Colombiano. Recuperado de http://www.elcolombiano.com/opinion/columnistas/ paramos-para-multinacionales-si-para-campesinos-no-DN1935858

Madrid E., Guzmán N., Medrano D., Mamani E. y Núñez R. (2002). Minería y comunidades campesinas en los Andes. ¿Coexistencia o conflicto?. Investigaciones Regionales, 2. La Paz: FUNDACION PIEB.

Perdomo, J. (2014). Minería en el suroeste antioqueño: ¿y qué pasa con los campesinos?. En: Foro del Suroeste Diálogo de Saberes y Oportunidad de región. Antioquia, 23 y 24 de octubre.

Quiroga, A. (2012). Construcción del territorio minero campesino en el nordeste de Antioquia, Colombia, movimientos socio territoriales y derechos humanos en contra del modelo económico multinacional 1970-2010 (tesis pregrado). Bogotá, Colombia: Universidad Nacional de Colombia.

Robles, R. (2001). Minería y comunidades campesinas (Ponencia). En: III Congreso Nacional de Investigaciones Antropológicas del Perú. Congreso llevado a cabo en Arequipa, Perú, Universidad Nacional Mayor de San Marcos, agosto 2001.

Rodríguez, D. (2014). La resistencia de ambientalistas y campesinos contra la gran minería. (7 de abril de 2016). Las 2 orillas. Recuperado de http://www.las2orillas.co/la-resistenciade-ambientalistas-y-campesinos-contra-la-gran-mineria/

Semana (2012). Así es la Colombia rural. (12 de abril de 2016). Semana.com. Recuperado de http://www.semana.com/especiales/pilares-tierra/asi-es-la-colombia-rural.html 